\title{
Ne zaman tibial osteotomi, ne zaman unikondiler artroplasti?
}

\author{
High tibial osteotomy versus unicondylar knee arthroplasty
}

\author{
Ibrahim Tuncay, Ahmet Can Erdem
}

Bezmialem Vakıf Üniversitesi Tıp Fakültesi, Ortopedi ve Travmatoloji Anabilim Dalı, İstanbul

\begin{abstract}
Son yıllarda artan iş temposu, sağlıksız beslenme, obezite ve çevresel faktörlerin etkisi gibi nedenlerle diz ekleminden kaynaklanan şikayetler giderek artış göstermektedir. Diz osteoartriti en sık görülen eklem hastalığıdır ve 60 yaş üzeri bireylerde semptomatik olarak erkeklerin \%10'unda, kadınların \%13'ünde görülür. Yaşam boyu semptomatik diz osteoartriti gelişme ihtimali \%45'tir. Diz osteoartriti multifaktöriyel bir hastalık olarak tanımlanmıştır ve biyolojik ve mekanik olayların kombinasyonu olarak ortaya çıkar. Diz osteoartriti genellikle medial kompartmandan başlar. Cerrahi seçenek olarak; hastaların yaşına, aktivite derecesine, deformitenin özelliklerine ve dejenerasyonun yaygınlığına bağlı olarak değişiklik gösterebilir. Bunlar arasında tibial osteotomi, unikondiler diz artroplastisi ve total diz artroplastisi sayılabilir. Bu tedavilerin başarısında hasta şeçiminin önemi akıldan çıkarılmamalıdır.
\end{abstract}

Anahtar sözcülkler: anteromedial osteoartrit; unikondiler diz protezi; proksimal tibial ostetomi
In recent years, complaints from the knee joint have been increasing day by day due to increased work pace, unhealthy diet, obesity and the effect of environmental factors. Knee osteoarthritis is the most common joint disease and is symptomatic in $10 \%$ of men and in $13 \%$ of women, who is over 60 years old. The probability of developing symptomatic knee osteoarthritis for life is $45 \%$. Knee osteoarthritis has been described as a multifactorial disease and occurs as a combination of biological and mechanical events. Knee osteoarthritis usually starts from the medial compartment. As a surgical option, it may vary depending on the age of the patients, the degree of activity, the characteristics of the deformity and the extent of degeneration. These options include tibial osteotomy, unicondylar knee prosthesis and total knee prosthesis. The importance of patient selection should be kept in mind for the success of these treatments.

Key words: anteromedial osteoarthritis; unicondylar knee prosthesis; total knee prosthesis
$\mathbf{P}$ roksimal tibial osteotomi ve unikondiler diz artroplastisi; diz medial kompartman artrozunun cerrahi tedavisinde kullanılan çok farklı iki yöntemdir. ${ }^{[1]}$ Bazı durumlarda aynı endikasyonları paylaşsalar da farklı felsefelerle çok farklı prosedürlere sahiptirler. Bazı yazarlar bunları alternatif cerrahi seçenekler olarak tanımlamaktadır. ${ }^{[1-3]}$

Tibial osteotomiler; dizde dizilim bozukluğunun eşlik ettiği tek kompartman artrozunun cerrahi tedavisi için başarılı ve yaygın olarak uygulanan bir prosedür olarak kabul edilmektedir. Unikondiler diz artroplastisi ise; unikompartmantal artroz tedavisinde total diz artroplastisi ve tibial osteotomilere mevcut tek alternatif tedavi olduğundan yüksek popülerlik kazanmıştır. ${ }^{[1]}$

\section{Proksimal Tibial Osteotomi}

Tibial osteotomilerin asıl amacı, başlangıç artrozunu belirleyen dizin açısal deformitesini veya metafizyel tibial dizilim bozukluğunu düzelterek semptomatik medial aşırı yüklenmeyi azaltmaktır.

Tibial osteotomiler için ideal hasta ${ }^{[1]}$;

1) Genç (60 yaşından küçük)

2) Hafif medial kompartman tutulumu olan (Ahlback sınıflandırması, Evre 1-2) hafif-orta derecede varus dizilimi $\left(5^{\circ}\right.$ ila $\left.15^{\circ}\right)$ olan semptomatik aktif hasta

3) Lateral ve patella-femoral kompanentler intakt

4) İyi bir eklem hareket açıklığı (diz fleksiyonu $>120^{\circ}$ )

5) Eklem laksitesi veya instabilitenin olmaması

- İletişim adresi: Prof. Dr. İbrahim Tuncay, Bezmialem Vakıf Üniversitesi Tıp Fakültesi, Ortopedi ve Travmatoloji Anabilim Dalı, İstanbul Tel: 0532 - 4116183 e-posta: ituncay@gmail.com

- Geliş tarihi: 20 Şubat $2020 \quad$ Kabul tarihi: 11 Mart 2020 

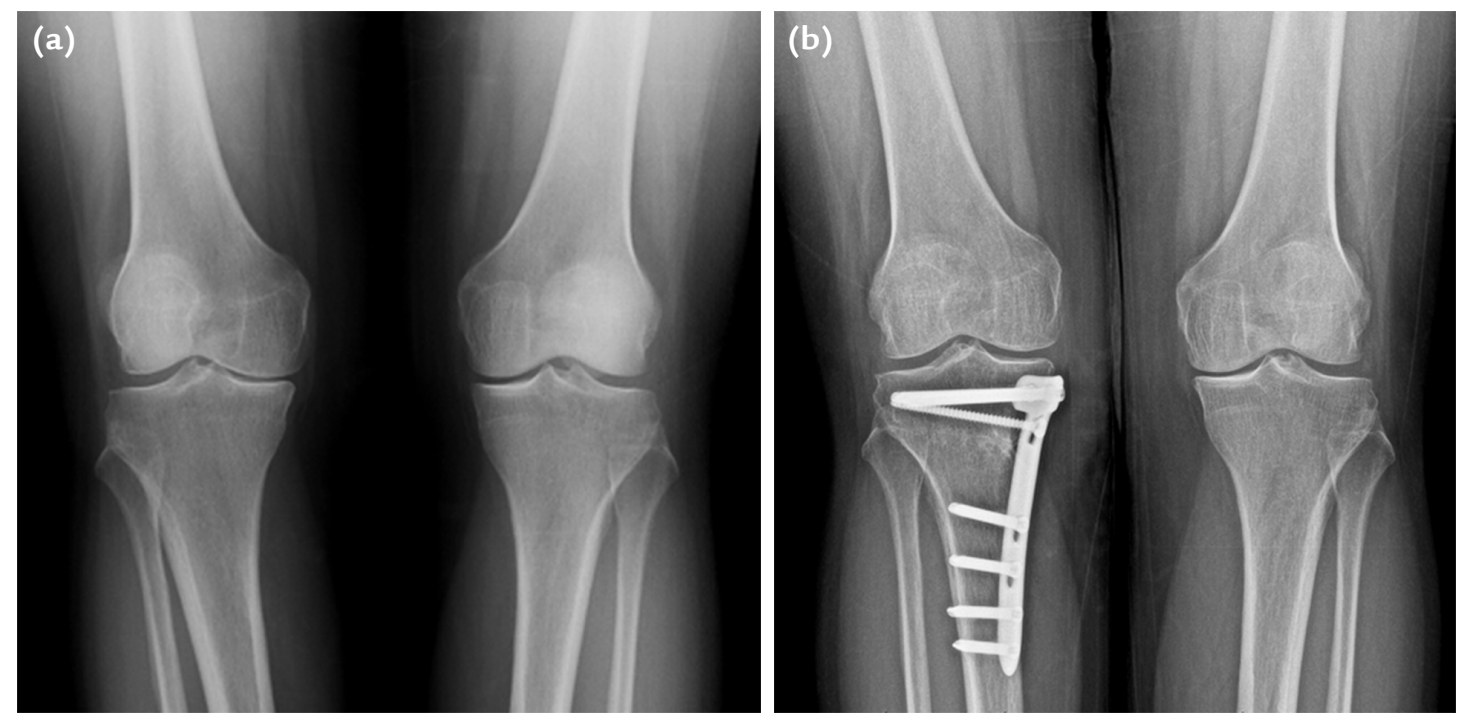

Şekil 1. a, b. Medial açık kama osteotomi uygulanan hastanın ameliyat öncesi (a) ve ameliyat sonrası 1. yıldaki (b) grafileri.

Bununla birlikte, tibial ostetomi endikasyonları için yakın zamanda, posterolateral laksite ve varus hiperekstansiyon itmesi (thrust) olan, ön çapraz bağ (ACL) eksikliği ile dizilim bozukluğu olan, kombine ligaman laksitesi ile posterolateral itmesi (thrust) olan hastalarda uygulanabilecek şekilde genişletilmiştir. ${ }^{[2]}$ Diz stabilitesinde tibial eğimin (slop) önemi ve multiplanar hizalamanın düzeltilmesine izin veren modern cerrahi tekniklerin gelişmesi, endikasyon açısından bu genişlemeye yol açmıştır. ${ }^{[3]}$ Hastanın vücut kitle indeksi (VKi) tartışmalı bir faktördür. Aslında, obezitenin tibial ostetomilerin sonucunu önemli ölçüde etkileyip etkilemediği henüz kanıtlanamamıştır. ${ }^{[4]}$

Son on yılda, genç hastalarda sonuçları iyileştirmek için tibial osteotomiler ile birlikte; kıkırdak resurfacing prosedürleri, menisküs nakli ve ön çapraz bağ rekonstrüksiyonu gibi prosedürler uygulanmış ve olumlu sonuçlar elde edilmiştir. ${ }^{[5]}$

Medial kompartmanı etkileyen osteoartritin derecesi, tibial osteotimi sonrası başarıyı belirlemede anahtar bir faktördür. Dizilim bozukluğu olan dizlerde fokal kondral defektlerin tedavisi için uygulanan tibial osteotomiler, kıkırdak onarım prosedürleri ilişkilendirilmiş olsa da, medial kompartmanın ciddi dejeneratif tutulumu tibial ostetomiler için hala bir kontrendikasyondur. ${ }^{[6]}$

Lateral ve patellofemoral kompartmanın artritik tutulumu bir başka kontrendikasyondur. Medial kompartman artrozu için uygulanan tibial osteotomilerin; sağlıklı bir dizde gerçekleştirilmesi durumunda, lateral veya patellofemoral kompartmanlarda dejeneratif değişiklik meydana getirmediği gösterilmiştir. Öte yandan, dizin iki veya üç kompartmanlı artrozu ile ilgili semptomları gerilettiği ise görülmemiştir. ${ }^{[7-9]}$

Proksimal tibial osteotomi hasta seçiminde bir diğer önemli faktör ise yaştır. Başarısızlık riski yılda \%7,6 artar ve 65 yaşın üzerindeki hastalarda göreceli risk genç hastaların 1,5 katıdır. Bu nedenle, 65 yaşından büyük hastalarda tibial ostetomiler önerilmemektedir (Şekil 1). ${ }^{[10]}$

\section{Unikondiler Diz Artroplastisi}

Unikondiler diz artroplastisi diz ekleminin kısmi yüzey replasmanıdır. Ciddi şekilde hasar görmüş bir bölmeyi değiştirme olasılığı, kemik stoğunun korunması ile birlikte total diz artroplastisine kıyasla daha hızlı iyileşme süresi ve minimal invaziv olması nedeniyle artan popülarite kazanmaktadır. ${ }^{[1,11]}$

Unikondiler diz artroplastisinin genel kabul gören ideal hastaları; $10^{\circ}$ 'den az varus ve $5^{\circ}$ 'den az valgus deformitesi ile birlikte noninflamatuar tek kompartman tutulumlu osteoartriti olan olgulardır. Unikondiler diz artroplastisinin en yaygın endikasyonu anteromedial osteoartrittir. ${ }^{[12-14]}$

\section{TEMEL PRENSIPLER}

Unikondiler diz artroplastisinde amaç kemik yüzeylere tam oturan iyi tespit edilmiş bir protezle beraber normal mekanik aksın sağlanmasıdır. Femoral ve tibial kesilerle, yumuşak doku dengelenmesiyle bu amaca ulaşılmaya çalışılır. 


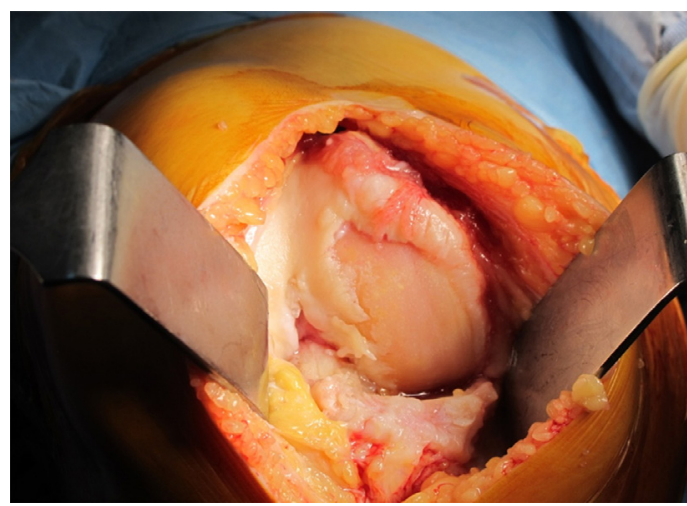

Şekil 2. Medial femoral kondilde Ahlback Evre IV artroz.

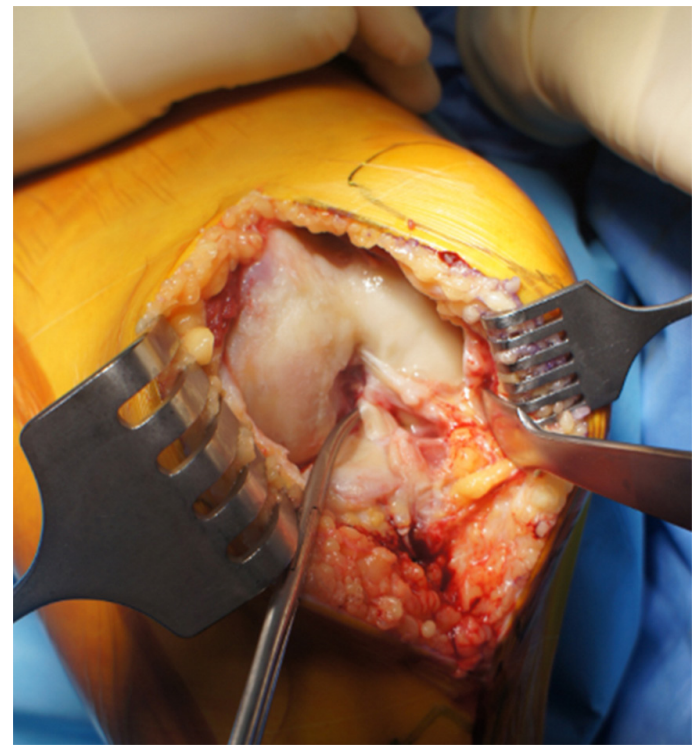

Şekil 4. Intakt ve fonksiyonel ÖÇB, lateral kompartmanda sağlam kıkırdak.

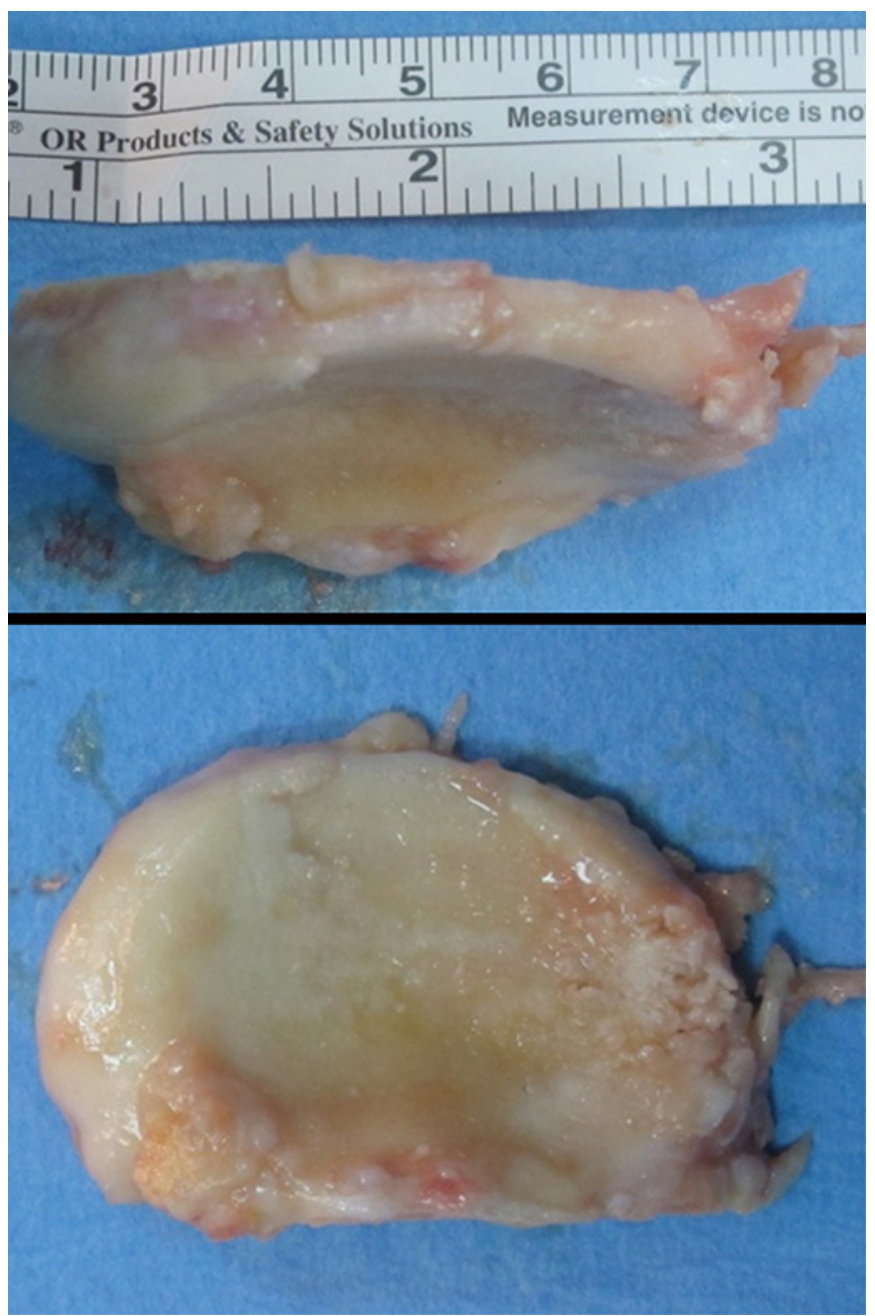

Şekil 3. Medial tibia platosu (anteromedial artroz - Ahlback Evre IV, posterior intakt).

\section{Ne Zaman ve Hangi Özelliklere Sahip Hastalara Unikondiler Diz Protezi Uygulayalım?}

Unikondiler diz protezinin en yaygın endikasyonu anteromedial osteoartrittir. Diğer endikasyonlar ise dizin fokal spontan osteonekrozu ve posttravmatik osteoartritidir. ${ }^{[15]}$

Unikondiler diz protezi endikasyonu koymak için aşağıdaki şartlar mutlaka aranmalıdır ${ }^{[16]}$ :

\section{Fiziksel bulgular}

1) Eklem protezini gerektirecek düzeyde ağrı

2) $15^{\circ}$ 'nin altında fleksiyon deformitesi

\section{Radyolojik bulgular}

3) Medial kompartmanda eburne kemiğin olması (Ahlback Evre 2, 3 veya 4) (Şekil 2)
4) Lateral kompartmanda tam kalınlıkta kıkırdak olması

5) Medial tibial platonun posteriorunda tam sağlam artiküler yüzey (Şekil 3)

$6)$ Elle düzeltilebilen varus deformitesi $\left(20^{\circ}\right.$ fleksiyonda)

\section{Ameliyat sırasında bulgular}

7) Tam ve fonksiyonel bir ÖÇB'nin varlığı (Şekil 4)

Unikondiler diz protezi bir artroplasti çeşidi olduğu için, genel olarak artroplastilerin kontrendike olduğu tüm durumlarda uygulanmamalıdır.

Kesin kontrendikasyonları; aktif ya da yakın zamanda geçirilmiş diz enfeksiyonu, kas güçsüzlüğü ile birlikte seyreden genu rekurvatum, şiddetli vasküler hastalık. ${ }^{[17,18]}$ Göreceli kontrendikasyonlar; genel sağlık 
durumunun kötü olması, cilt sorunları, ileri derecede osteoporoz, periferik dolaşım bozukluğu, hasta uyumsuzluğudur. ${ }^{[15,16]}$

\section{UDP (Unikondiler Diz Protezi)'ye Özel Kontrendikasyonlar}

İnflamatuar artrit sinovyumun hastalığıdır ve eklemin her yerini tutan artrit çeşididir. Bundan dolayı UDP için kontrendikedir. Cerrah, inflamatuar artritin başlangıç safhasında anteromedial artrit olabilme olasılığından dolayı dikkatli olmalıdır. Hastadan alınacak ayrıntılı bir anamnez ve hastaya yapılacak dikkatli bir fizik muayene ile ayırıcı tanıyı koymalıdır. İnflamatuar artritin sonraki safhalarında diz ekleminin tüm kompartmanlarında tutulum olacağından dolayı başarısız sonuçlar kaçınılmazdır. ${ }^{[15,16]}$

Anatomik kontrendikasyonları ise ${ }^{[16]}$;

1. Ön çapraz bağın olmaması veya ciddi hasar gördüğü dizlerde (veya arka çapraz bağ veya iç yan bağ)

2. Medial kompartmanda eburne kemik varlığının gösterilememesi

3. Eklem varusunun tam düzeltilemediği durumlarda

4. $15^{\circ}$ 'den fazla fleksiyon deformitesi

5. $100^{\circ}$ 'nin altında fleksiyon (anestezi altında)

6. Lateral kompartman yük binme alanında kıkırdağın incelmesi veya aşınması

7. Patellofemoral eklemde eburne kemik olması

8. Daha önce yüksek tibial osteotomi yapılması

Unikondiler artoplasti ve tibial osteotomi arasındaki endikasyonlardaki farklılıklara rağmen, küçük bir hasta popülasyonu her iki cerrahi prosedür için uygun kabul edilebilir. ${ }^{[1]}$

1. 55 ila 65 yaş arası hastalar

2. Orta derecede aktif

3. Obez olmayan

4. Hafif varus $\left(5-10^{\circ}\right)$

5. Eklem instabilitesi olmaması

6. İyi eklem hareket açılığı ( $5^{\circ}$ 'den az fleksiyon kontraktürü)

7. Orta derecede unikompartmental artrit.

Hem tibial osteotomi hem de unikondiler artroplasti medial kompartman diz artrozunu tedavi için etkili olsa da, eşdeğer tedavi seçenekleri olarak düşünülmemelidir. Her iki teknikle öngörülebilir iyi sonuçlar elde etmek için doğru hasta seçimi çok önemlidir.

\section{KAYNAKLAR}

1. Dettoni F, Bonasia DE, Castoldi F, Bruzzone M, Blonna D, Rossi R. High tibial osteotomy versus unicompartmental knee arthroplasty for medial compartment arthrosis of the knee: a review of the literature. lowa Orthop J 2010;30:131-40. https://www.ncbi.nlm.nih.gov/pmc/articles/PMC2958284/

2. Amendola A. The Role of Osteotomy in the Multiple Ligament Injured Knee. Arthroscopy 2003;19(Suppl 1):11-13. Crossref

3. Rossi R, Bonasia DE, Amendola A. The Role of High Tibial Osteotomy in the Varus Knee. J Am Acad Orthop Surg 2011;19(10):590-9. Crossref

4. Wright JM, Crockett HC, Slawski DP, Madsen MW, Windsor RE. High tibial osteotomy. J Am Acad Orthop Surg 2005;13(4):279-89. Crossref

5. Bonasia DE, Dettoni F, Sito G, Blonna D, Marmotti A, Bruzzone M, Castoldi F, Rossi R. Medial opening wedge high tibial osteotomy for medial compartment overload/arthritis in the varus knee: prognostic factors. Am J Sports Med 2014;42(3):690-8. Crossref

6. Ferruzzi A, Buda R, Cavallo M, Timoncini A, Natali S, Giannini S. Cartilage repair procedures associated with high tibial osteotomy in varus knees: clinical results at 11 years' follow-up. Knee 2014;21(2):445-50. Crossref

7. Majima T, Yasuda K, Katsuragi R, Kaneda K. Progression of joint arthrosis 10 to 15 years after high tibial osteotomy. Clin Orthop Relat Res 2000;381:177-84. Crossref

8. Fu D, Li G, Chen K, Zhao Y, Hua Y, Cai Z. Comparison of high tibial osteotomy and unicompartmental knee arthroplasty in the treatment of unicompartmental osteoarthritis: a metaanalysis. J Arthroplasty 2013;28(5):759-65. Crossref

9. Brouwer RW, Huizinga MR, Duivenvoorden $T$, van Raaij TM, Verhagen AP, Bierma-Zeinstra SM, Verhaar JAN. Osteotomy for treating knee osteoarthritis. Cochrane Database Syst Rev 2014;12:CD004019. Crossref

10. Trieb K, Grohs J, Hanslik-Schnabel B, Stulnig T, Panotopoulos J, Wanivenhaus A. Age predicts outcome of high-tibial osteotomy. Knee Surg Sports Traumatol Arthrosc 2006;14(2):149-52. Crossref

11. Aglietti P, Miehlke EK, Neyret P, et al. Florence, Italy: 2007. Symposium: The future in TKA: 2007 vs 2015: Will it all be MIS and CAS Presented at the 2007 International Society of Arthroscopy, Knee Surgery and Orthopaedic Sports Medicine Congress. May 27-31.

12. Nwachukwu BU, McCormick FM, Schairer WW, Frank RM, Provencher MT, Roche MW. Unicompartmental knee arthroplasty versus high tibial osteotomy: United States practice patterns for the surgical treatment of unicompartmental arthritis. J Arthroplasty 2014;29(8):1586-9. Crossref

13. Lobenhoffer P, Agneskirchner JD. Osteotomy around the knee vs. Unicondylar knee replacement. Orthopade 2014;43(10):923-9. Crossref

14. Saragaglia D, Rouchy RC, Krayan A, Refaie R. Return to sports after valgus osteotomy of the knee joint in patients with medial unicompartmental osteoarthritis. Int Orthop 2014;38(10):2109-14. Crossref

15. Tyagi V, Farooq M, Unicompartmental Knee Arthroplasty: Indications, Outcomes, and Complications. Conn Med 2017;81(2):87-90.

16. O'Connor J, Pandit H, Dodd C, Goodfellow J. Unicompartmental Arthroplasty with The Oxford Knee, 2011, ePub eBook. Crossref

17. Kozinn S, Scott R. Current concepts review: unicondylar knee arthroplasty. J Bone Joint Surg Am 1989;71(1):145-50. Crossref

18. Goodfellow JW, O'Connor JJ. Oxford Knee (femoral). UK, French, German, Swiss Patent EP0327397, Irish Patent 62951, US Patent 1989,5314482. 